3 Beers SR, Rosenberg DR, Dick EL, Williams T, O'Hearn KM, Birmaher B, et al. Neuropsychological study of frontal lobe function in psychotropic-naive children with obsessive-compulsive disorder. Am J Psychiatry 1999; 156: 777-9.

4 Hollander E, Schiffman E, Cohen B, Rivera-Stein MA, Rosen W, Gorman JM, et al. Signs of central nervous system dysfunction in obsessive-compulsive disorder. Arch Gen Psychiatry 1990; 47: 27-32.

5 Roth RM, Milovan D, Baribeau J, O'Connor K. Neuropsychological functioning in early- and late-onset obsessive-compulsive disorder. J Neuropsychiatry Clin Neurosci 2005; 17: 208-13.

6 Bolton D, Raven P, Madronal-Luque R, Marks IM. Neurological and neuropsychological signs in obsessive compulsive disorder: interaction with behavioural treatment. Behav Res Ther 2000; 38: 695-708.

Imran Mushtaq, Northampton Child and Adolescent Mental Health Service, 8 Notre Dame Mews, Northampton NN1 2BG, UK. Email: imranmushtaq@doctors.org.uk; Muhammad Nabeel Helal, Cabot Child and Adolescent Mental Health Service, Bristol, UK

doi: 10.1192/bjp.195.6.554

Authors' reply: Although Drs Mushtaq \& Helal noted the need for longitudinal studies in this area, they expressed several concerns, one regarding the small number of individuals with OCD in our study. We agree and noted this limitation in our original paper. We were constrained, however, by the prevalence of OCD in the population; the proportion of cohort members diagnosed with OCD at age 32 in our study $(1.9 \%)$ was consistent with other epidemiological studies. Our conclusions nonetheless remain tentative until they may be replicated in another longitudinal study.

Drs Mushtaq \& Helal also referred to a previously published study by our group, which examined risk factors for an OCD diagnosis at age 18 . We have suggested that this discrepancy may be related to changes in the OCD criteria from DSM-III to DSM-IV, which reduced the reported prevalence of the disorder in the general population. ${ }^{1}$ Study members diagnosed with OCD at age 32 may have represented a more severe and persistent subgroup relative to the larger proportion (4\%) of cohort members diagnosed with OCD at age 18 .

They refer to a cross-sectional study, conducted by Beers et al, that failed to find cognitive deficits in a group of 21 children diagnosed with OCD. ${ }^{2}$ Although this study made a valuable contribution, the authors themselves noted the need to supplement their findings with results from 'carefully designed longitudinal studies.' ${ }^{3}$ We suspect that the discrepancy between the results of this earlier study and our recent findings may be partially attributable to sampling differences, including referral bias. Participants in the earlier study were paediatric patients with OCD at a prestigious psychiatric institute, whereas the Dunedin cohort comprises a non-treatment-seeking population cohort from a range of socioeconomic backgrounds. Further, in the previous study, children with OCD who had a lifetime history of any other psychiatric diagnosis were excluded. ${ }^{2}$ Obsessivecompulsive disorder, like most emotional disorders, is highly comorbid with other psychiatric conditions. ${ }^{4}$ Although creating a 'pure' OCD group eliminates the influence of comorbid disorders, this advantage must be weighed against the likelihood of creating a non-representative, potentially less severe subgroup. Our study aimed to test for neuropsychological risk factors for adult OCD, as it presents in the general population, including comorbidity, and regardless of referral and treatment seeking. Thus, our study's aims, design and inferences differed decidedly from those of Beers et al.

Finally, Drs Mushtaq \& Helal made the valid point that poor performance on neuropsychological tests may help to localise dysfunction in particular neuroanatomical substrates, but it does not provide conclusive evidence for the cause of the pathology. Although our results are consistent with research that has demonstrated that children with OCD already show abnormalities in frontal and striatal volumes relative to comparison participants, ${ }^{5}$ we do not suggest that we have provided definitive evidence of causality. Obsessive-compulsive disorder is likely to be multiply determined and not all participants with particular neuropsychological deficits will go on to develop this disorder.

1 Crino R, Slade T, Andrews G. The changing prevalence and severity of obsessive-compulsive disorder criteria from DSM-III to DSM-IV. Am J Psychiatry 2005; 162: 876-82.

2 Beers SR, Rosenberg DR, Dick EL, Williams T, O'Hearn KM, Birmaher B, et al. Neuropsychological study of frontal lobe function in psychotropic-naive children with obsessive-compulsive disorder. Am J Psychiatry 1999; 156 777-9.

3 Beers SR, Rosenberg DR, Ryan CM. Cognitive deficits in obsessive-compulsive disorder: Dr Beers and colleagues reply. Am J Psychiatry 2000; 157: 1183.

4 Brown TA, Campbell LA, Lehman CL, Grisham JR, Mancill RB. Current and lifetime comorbidity of the DSM-IV anxiety and mood disorders in a large clinical sample. J Abnorm Psychology 2001; 110: 585-99.

5 Rosenberg DR, Keshavan MS. Toward a neurodevelopmental model of obsessive-compulsive disorder. Biol Psychiatry 1998; 43: 623-40.

Jessica R. Grisham, School of Psychology, University of New South Wales, Sydney, Australia 2052. Email: jessicag@unsw.edu.au; Terrie E. Moffitt, Institute of

Psychiatry, King's College London, UK and Duke University, Durham, North Carolina, USA; Richie Poulton, Dunedin School of Medicine, University of Otago, New Zealand.

doi: 10.1192/bjp.195.6.555

\section{James Joyce and Asperger syndrome}

As an Irishman, I was pleased to learn both of Peter Tyrer's Celtic heritage and of his inclusion of Ulysses in his list of 'ten books.' I agree with Tyrer that the sheer poetic beauty and creative manipulation of language make this book a great work. The author correctly points out Joyce's amazing ability to describe emotions with both beauty and precision. I would like to add to this issue further; I believe it is Joyce's description of complex feeling states that is one of the supreme facets of Ulysses. In drawing a distinction between emotions and feelings I do so in the same sense that Antonio Damasio does, ${ }^{2}$ i.e. that feelings represent a composite of often numerous emotions further elaborated by various thought processes and felt in the viscera or body.

Joyce captures subtle feeling states so well that I was surprised to find, upon a recent trip to the 'auld sod', a book in a Dublin airport store suggesting that Joyce had Asperger syndrome. ${ }^{3}$ I thought it a somewhat odd hypothesis that a man who could describe emotions/feelings so well would have a disorder whose key pathology is an impaired theory of mind. As Tyrer alludes, Joyce's use of the 'stream of consciousness' technique in his writing is much more akin to thought disorder - this was particularly true of his last book, Finnegan's Wake. Although Joyce experienced certain difficulties in this life, there is little evidence to suggest he was ever psychotic; and his creative deconstruction of language was no doubt a reflection of his genius for writing. However, Joyce had a daughter who developed schizophrenia so if there was a suggestion of mental illness influencing his work, a psychotic trait seems a more plausible thesis to me than Asperger syndrome.

The second aspect of Tyrer's article that I enjoyed was his anecdote of the late, great Aubrey Lewis berating a psychiatry trainee at the Maudsley Hospital for failing to have 